\title{
Absorptance of nonferrous alloys to Nd:YLF and Nd:YAG laser light at room temperature
}

\author{
D. Bergström, J. Powell, and A. F. H. Kaplan
}

\begin{abstract}
The measurement of absorptance is important for the analysis and modeling of laser-material interactions. Unfortunately, most of the absorptance data currently available consider only polished pure metals rather than the commercially available (unpolished, oxidized) alloys that are actually being processed in manufacturing. We present the results of absorptance measurements carried out at room temperature on as-received engineering grade nonferrous metals ( $\mathrm{Al}, \mathrm{Cu}$, and $\mathrm{Zn}$ alloys). The measurements were made using an integrating sphere with a Nd:YLF laser at two wavelengths (1053 and $527 \mathrm{~nm}$, which means that the results are also valid for Nd:YAG radiation at 1064 and $532 \mathrm{~nm}$ ). The absorptance results obtained differ considerably from the existing data for polished, pure metals and should help improve the accuracy of laser-material interaction models. Some clear trends were identified. For all 22 cases studied the absorptance was higher than for ideal pure, polished metals. For all $\mathrm{Al}$ and $\mathrm{Cu}$ samples the absorptance was higher for the green than it was for the infrared wavelength, while for all $\mathrm{Zn}$ coatings this trend was reversed. No clear correlation between absorptance and surface roughness was found at low roughness values (Sa 0.15-0.60), but one rougher set of samples (Sa 2.34) indicated a roughnessabsorptance correlation at higher roughness levels. (C) 2007 Optical Society of America
\end{abstract}

OCIS codes: $140.3390,120.3150,240.5770,120.6660$.

\section{Introduction}

In laser materials processing of metals, an understanding of the laser absorption mechanisms plays a vital role in determining the optimum processing parameters. The absorptance, which is the fraction of the incident laser light that is absorbed, depends on a number of different parameters, the most important of which are listed in Table $1 .^{1}$ (Absorptivity is a term restricted to flat, pure surfaces, absorptance is a more general term).

When modeling laser processing applications, such as cutting, welding, drilling, cladding, and hardening, it is important to model the absorption correctly. In very sophisticated models it may be necessary to have an analytical function for the different absorption mechanisms. In other, simpler, cases it may be suffi-

D. Bergström (david.bergstrom@miun.se) is with the Department of Engineering, Physics and Mathematics, Mid Sweden University, S-831 25 Ostersund, Sweden. J. Powell is with Laser Expertise Ltd., Nottingham, UK. A. F. H. Kaplan is with the Division of Manufacturing Systems Engineering, Lulea University of Technology, S-971 87 Lulea, Sweden.

Received 21 August 2006; revised 22 October 2006; accepted 29 October 2006; posted 7 November 2006 (Doc. ID 73612); published 20 February 2007.

0003-6935/07/081290-12\$15.00/0

(C) 2007 Optical Society of America cient to have an accurate average absorptance value to plug in. In any case, published data for the absorptance and reflectance of metals are usually presented only for perfectly pure, clean, and flat surfaces that are free from oxide layers (measurements are commonly done in vacuum). This is quite different from the normal situation found in real-life material processing applications. Most metal surfaces are rough to some extent, and oxide layers are more of a rule than an exception. Also, the concentration on pure metals has meant that there is very little information available for the absorptance of alloys (stainless steel and brass, for example), polished or otherwise. In real processing environments alloys are far more commonly used than pure metals. It is therefore generally inappropriate to use the published values of absorptance for pure polished surfaces in mathematical models of laser processing.

Figure 1 demonstrates some of the complexities of photon absorption by an engineering grade metal surface. Such a surface has a characteristic roughness and is always covered by an oxide layer. The surface roughness can result in multiple reflections that involve multiple absorption events [Fig. 1(b)]. Surface roughness can also involve the incoming radiation in absorption events at high angles of incidence, close to the Brewster angle. This can result in very high local absorptance levels. The oxide layer 
Table 1. Laser and Metal Properties of Importance to Absorption ${ }^{a}$

\begin{tabular}{ll}
\hline Laser Properties & \multicolumn{1}{c}{ Metal Properties } \\
\hline Wavelength & Chemical composition \\
Polarization & Temperature \\
Angle of Incidence & Roughness/topography \\
Intensity & Oxide layers \\
& Contamination (dust, dirt, surface defects) \\
\hline
\end{tabular}

${ }^{a}$ See Ref. 1.

may be absorbing in its own right or may be responsible for multiple reflections or waveguiding [Fig. 1(c)]. In addition to these effects the surface may be contaminated with material that has a higher absorptance than the underlying metal.

All of the above phenomena increase the absorptance of the surface in question, and the use of alloying elements will also tend to complicate the situation. For this reason the best way to establish the absorptance of an engineering metal surface is by direct measurement.

It would, of course, be extremely difficult to measure the absorptance of the molten, turbulent surfaces typical of laser welding or cutting. However, it is possible to accurately measure the absorptance of the solid material at room temperature, and the values obtained can provide an insight into how the materials behave at elevated temperatures. This can be argued from the fact that for metals, at wavelengths at approximately $1 \mu \mathrm{m}$, the temperature dependence of absorptance is small. It is well established that metals usually have a so-called $X$ point, a wavelength point or band where the temperature coefficient of absorptance changes sign. ${ }^{2}$ The reason for this kind of behavior lies in the different temperature coefficients for intraband (freeelectron) and interband (bound-electron) absorption, the two intrinsic absorption mechanisms prevalent in metals. Intraband absorption increases with temperature simply because the free electrons gain kinetic energy while the phonon population grows, which increases the electron-phonon collision frequency (i.e., the energy conversion efficiency between the light, the free electrons, and the lattice). Interband absorption, on the other hand, is much more complicated and depends on the particular band structure of the metal. The general principle is that as the temperature is elevated, the electron Fermi energy distribution function is smoothed out, and the absorption bands are broadened. The competition between these two effects leads to the $X$ point, which for most metals lies at a wavelength near $1 \mu \mathrm{m} .^{3}$

In any case, the absorptance of the solid material as opposed to the molten state is in itself very important for two reasons:

1. During the initiation of any weld or cut the laser is interacting with the solid surface.

2. During welding or cutting the leading edge of the laser beam in many cases interacts with the solid surface of the material.

A comprehensive literature survey with 46 references on experimental absorption measurement meth-

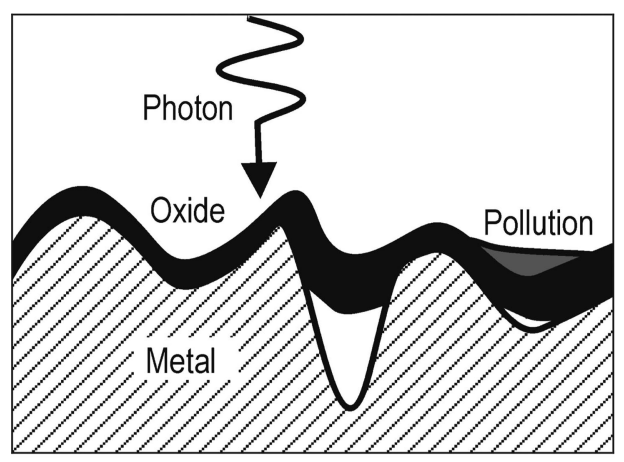

(a)

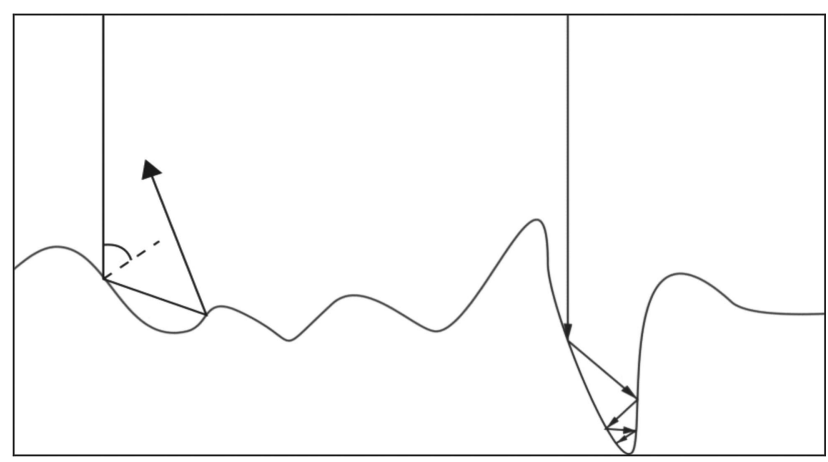

(b)

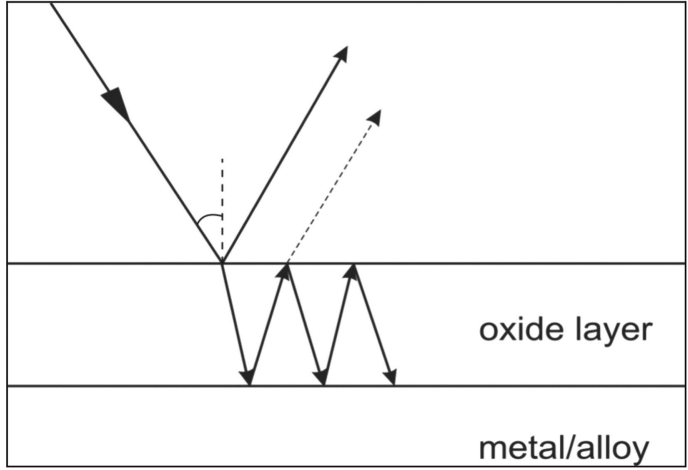

(c)
Fig. 1. Some of the mechanisms that increase the absorptivity of real engineering surfaces. (a) Typical cross section of an engineering surface, (b) high (Brewster) angle absorptance and multiple reflections due to surface roughness, (c) multiple reflections within an oxide layer. 


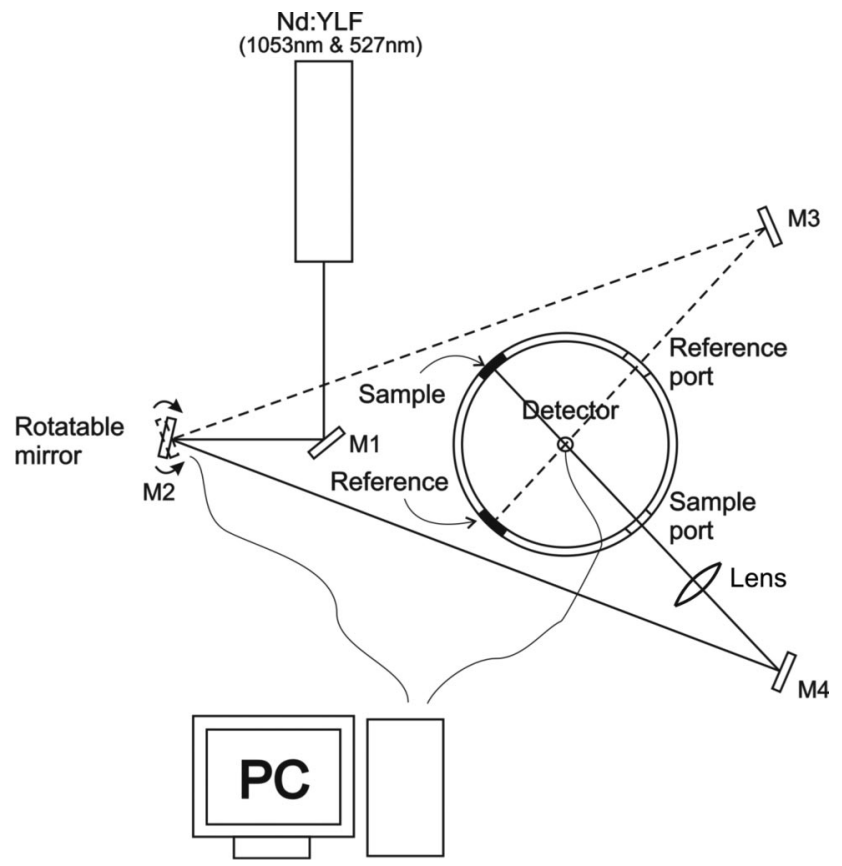

Fig. 2. Experimental setup for measuring reflectance.

ods has been prepared by the present authors. ${ }^{4}$ In addition the authors have provided a comprehensive literature survey on the theory and modeling of the absorption mechanisms in metals, ${ }^{1}$ with reference to 47 publications.

This paper presents the results of an experimental survey of the room-temperature absorptance of a wide range of as-received commercially available alloys. There are a number of different experimental methods available for measuring laser absorptance in opaque solids. Some of the more commonly used are laser calorimetry, gonioreflectometry, integrating sphere or integrating mirror reflectometry, and emittance spectroscopy. ${ }^{4}$

In this paper reflectometry using an integrating sphere was selected, mainly because integrating spheres are commercially available, relatively inexpensive,

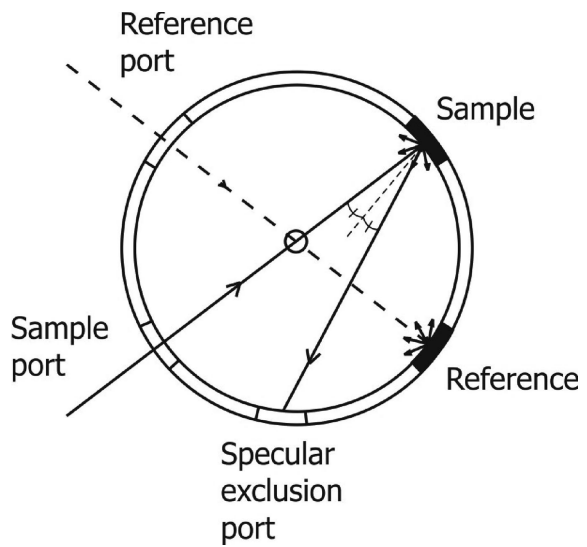

Fig. 3. Optical diffusivity can be measured by excluding the specular fraction of the reflected light through an empty port or by fitting a light trap.

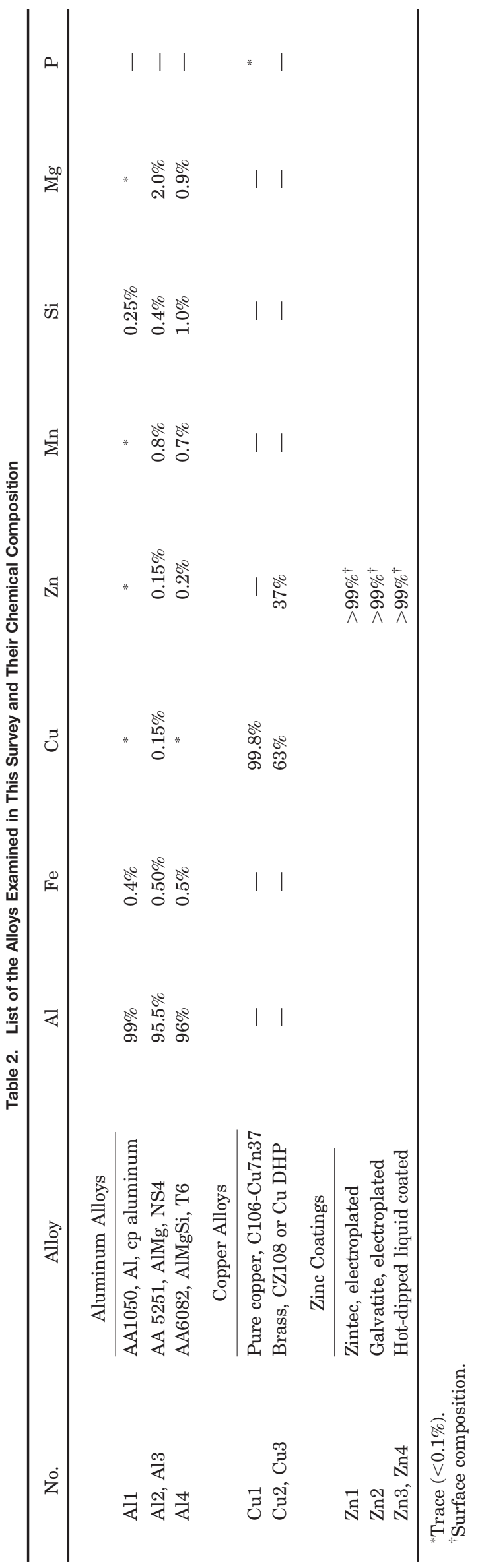




\begin{tabular}{|c|c|c|c|c|c|c|}
\hline No. & Alloy & Surface & Percent & Isotropic & $\begin{array}{c}S_{a} \\
{[\mu \mathrm{m}]}\end{array}$ & $\begin{array}{c}S_{q} \\
{[\mu \mathrm{m}]}\end{array}$ \\
\hline & Aluminum Alloys & & $\mathrm{Al} \%$ & & & \\
\hline $\mathrm{Al} 1$ & AA1050 & Cold rolled & $99 \%$ & $\mathrm{~N}$ & 0.25 & 0.32 \\
\hline $\mathrm{Al} 2$ & AA5251 & Cold rolled, $3 \mathrm{~mm}$ thick & $95.5 \%$ & $\mathrm{~N}$ & 0.28 & 0.35 \\
\hline $\mathrm{Al} 3$ & AA5251 & Cold rolled, $6 \mathrm{~mm}$ thick & $95.5 \%$ & $\mathrm{~N}$ & 0.23 & 0.29 \\
\hline \multirow[t]{2}{*}{$\mathrm{Al} 4$} & AA6082 & Cold rolled & $96 \%$ & $\mathrm{~N}$ & 0.30 & 0.36 \\
\hline & Copper Alloys & & $\mathrm{Cu} \%$ & & & \\
\hline $\mathrm{Cu} 1$ & Pure Cu & Cold rolled & $99.8 \%$ & $\mathrm{~N}$ & 0.16 & 0.20 \\
\hline $\mathrm{Cu} 2$ & Brass & Cold rolled, nonpolished & $63 \%$ & $\mathrm{~N}$ & 0.50 & 0.62 \\
\hline \multirow[t]{2}{*}{$\mathrm{Cu} 3$} & Brass & Cold rolled, polished & $63 \%$ & $\mathrm{~N}$ & 0.54 & 0.66 \\
\hline & Zinc Coatings & & $\mathrm{Zn} \%$ & & & \\
\hline Zn1 & Zintec & Galvanized-electroplated & $>99 \%$ & $\mathrm{Y}$ & 2.34 & 2.77 \\
\hline $\mathrm{Zn} 2$ & Galvatite & Galvanized-electroplated & $>99 \%$ & $\mathrm{Y}$ & 0.52 & 0.68 \\
\hline Zn3 & Hot-dip Galv. & Hot-dipped-liquid coated & $>99 \%$ & $\mathrm{Y}$ & 0.33 & 0.43 \\
\hline Zn4 & Hot-dip Galv. & Hot-dipped-liquid coated & $>99 \%$ & $\mathrm{Y}$ & 0.58 & 0.78 \\
\hline
\end{tabular}

and easy to use while at the same time being very accurate and versatile. By measuring the reflectance $R$ of a sample, we get immediate information regarding the absorptance $A$, since $A=1-R$ for opaque solids.

Although all the following measurements were made using an Nd:YLF laser, the results are also valid for Nd:YAG lasers because the wavelengths of the two types of laser (1053 or $527 \mathrm{~nm}$ and 1064 or $532 \mathrm{~nm}$, respectively) differ by less than $1 \%$.

\section{Experimental Setup}

A. Instrumentation

The reflectance measurements were carried out in the laser laboratory at the Mid Sweden University,
Ostersund. The laser used as the radiation source was a $1 \mathrm{~W}$ cw Nd:YLF laser with a fundamental wavelength of $1053 \mathrm{~nm}$, equipped with a SHG (secondharmonic generation) crystal to also allow production of green light at $527 \mathrm{~nm}$.

The reflectance of the various metals was measured by using an integrating sphere in a double beam setup, as shown in Fig. 2. The $150 \mathrm{~mm}$ diameter six-port integrating sphere has a barium sulphate-based coating called Spectraflect, which has high reflective Lambertian properties for wavelengths between 300 and $2400 \mathrm{~nm}$.

The Nd:YLF laser beam was directed onto a rotatable mirror (M2 in Fig. 2) that was flipped between

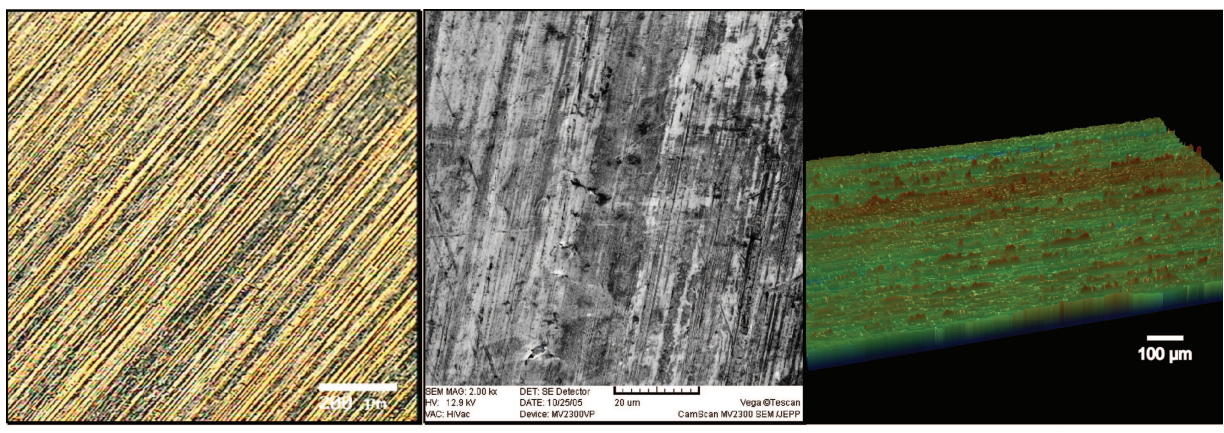

\begin{tabular}{|c|c|c|c|}
\hline \multicolumn{2}{|c|}{$\lambda=1053 \mathrm{~nm}$} & \multicolumn{2}{c|}{$\lambda=532 \mathrm{~nm}$} \\
\hline$A$ & $\sigma$ & $A$ & $\sigma$ \\
\hline $15.7 \%$ & $1.3 \%$ & $32.4 \%$ & $2.8 \%$ \\
\hline
\end{tabular}

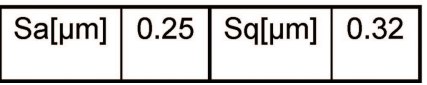

Fig. 4. (Color online) Al1: AA1050, commercially pure aluminium. 


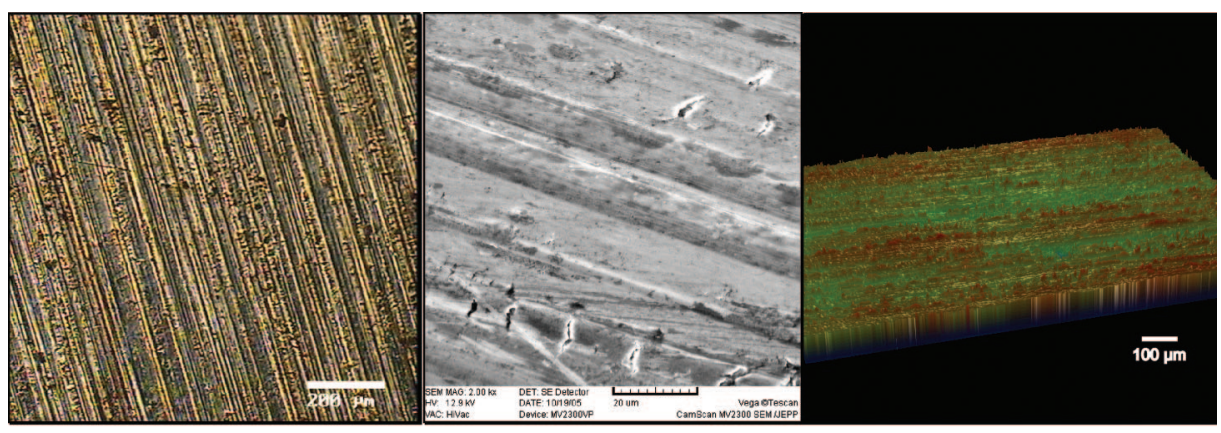

\begin{tabular}{|c|c|c|c|}
\hline \multicolumn{2}{|c|}{$\lambda=1053 \mathrm{~nm}$} & \multicolumn{2}{c|}{$\lambda=532 \mathrm{~nm}$} \\
\hline$A$ & $\sigma$ & $A$ & $\sigma$ \\
\hline $20.7 \%$ & $0.7 \%$ & $42.6 \%$ & $1.2 \%$ \\
\hline
\end{tabular}

\begin{tabular}{|l|l|l|l|}
\hline $\mathrm{Sa}[\mu \mathrm{m}]$ & 0.28 & $\mathrm{Sq}[\mu \mathrm{m}]$ & 0.35 \\
\hline
\end{tabular}

(a)

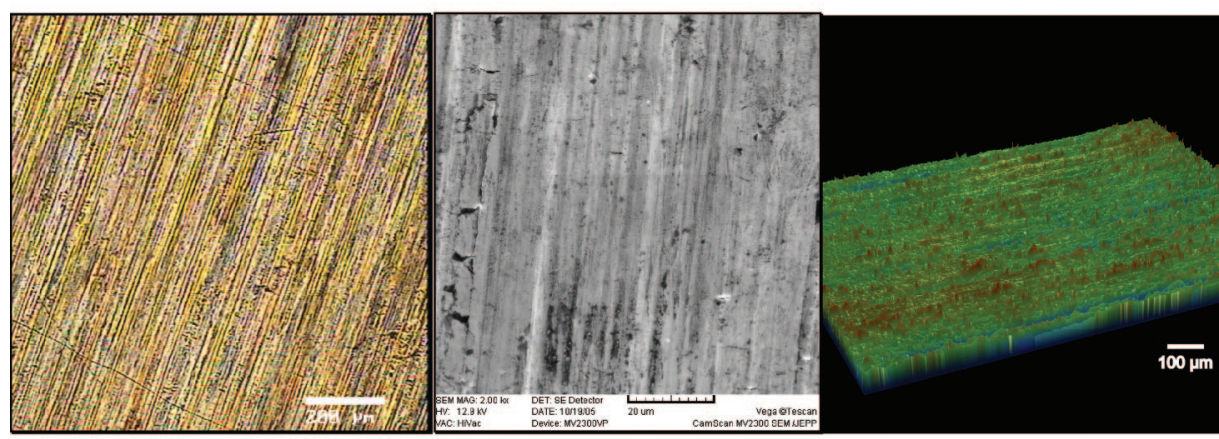

\begin{tabular}{|c|c|c|c|}
\hline \multicolumn{2}{|c|}{$\lambda=1053 \mathrm{~nm}$} & \multicolumn{2}{c|}{$\lambda=532 \mathrm{~nm}$} \\
\hline$A$ & $\sigma$ & $A$ & $\sigma$ \\
\hline $26.9 \%$ & $1.3 \%$ & $53.9 \%$ & $1.8 \%$ \\
\hline
\end{tabular}

\begin{tabular}{|l|l|l|l|}
\hline Sa[ $[\mu \mathrm{m}]$ & 0.23 & $\mathrm{Sq}[\mu \mathrm{m}]$ & 0.29 \\
\hline
\end{tabular}

(b)

Fig. 5. (Color online) AA5251, AlMg: (a) Al2: AlMg, 3 mm thick, (b) Al3: AlMg, 6 mm thick.

two positions to produce sample and reference beams. The flipping frequency was set to approximately $1 \mathrm{~Hz}$ to ensure mirror stability. Mirrors 3 and 4 (M3 and M4 in Fig. 2) then directed the beams onto the sample and reference, respectively, at an angle of incidence of $8^{\circ}$. As reference, a port plug of Spectraflect was used. After spatial integration by the sphere, the reflected light was then detected by a reverse biased $5.7 \mathrm{~mm}^{2}$ Si photodiode, with a spectral response between 190 and $1100 \mathrm{~nm}$. The voltage signal of the photodiode was finally digitized in an analog-to-digital (A/D) converter and sampled by a personal computer (PC).

The laser beam was partially focused from its original diameter of $10 \mathrm{~mm}$ to approximately $3 \mathrm{~mm}$ on the sample surface by using a lens with a diameter of $25 \mathrm{~mm}$ and a focal length of $150 \mathrm{~mm}$ (see Fig. 2). The port diameters (see Fig. 2) were $25 \mathrm{~mm}$. The samples were cleaned with isopropyl alcohol and dried before measurements were taken. In all cases the samples were checked for differences in reflectance as a function of any directional surface structure. This was done by rotating the sample between measurements. For these samples no correlation between surface structure orientation and reflectance was observed.

\section{B. Error Correction Methods}

Several correction methods were applied to the reflectance measurements to improve accuracy and 


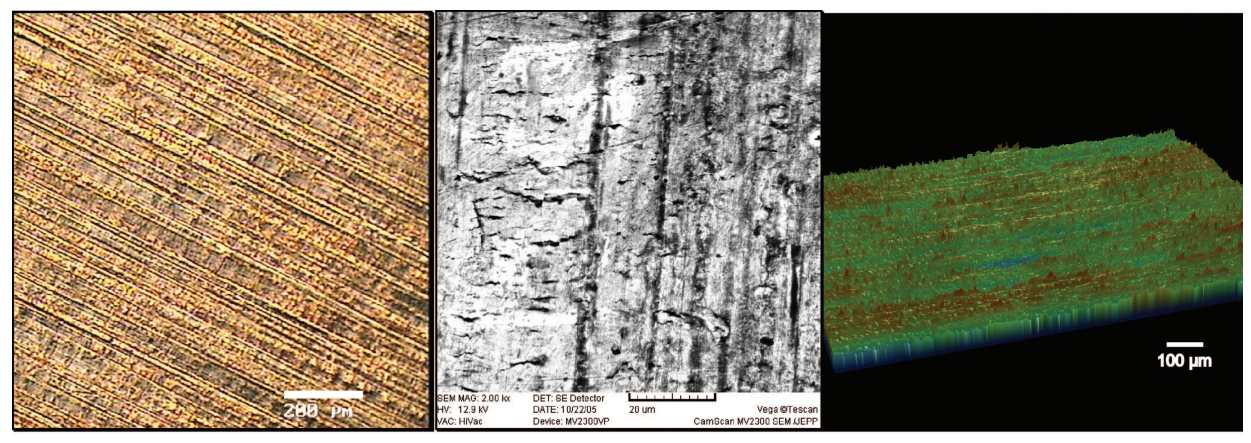

\begin{tabular}{|c|c|c|c|}
\hline \multicolumn{2}{|c|}{$\lambda=1053 \mathrm{~nm}$} & \multicolumn{2}{c|}{$\lambda=532 \mathrm{~nm}$} \\
\hline $\mathrm{A}$ & $\sigma$ & A & $\sigma$ \\
\hline $23.9 \%$ & $1.3 \%$ & $39.3 \%$ & $3.0 \%$ \\
\hline
\end{tabular}

\begin{tabular}{|l|l|l|l|}
\hline $\mathrm{Sa}[\mu \mathrm{m}]$ & 0.30 & $\mathrm{Sq}[\mu \mathrm{m}]$ & 0.36 \\
\hline
\end{tabular}

Fig. 6. (Color online) Al4: AA6082, AlMgSi.

minimize errors. Clarke and Compton ${ }^{5}$ have identified the following main sources of error in integrating sphere reflectometers:

(a) Light losses through ports in the sphere wall.

(b) Unequal illumination of the sample and standard and changes in throughput when a single beam method is used.

(c) Directional dependence of light scattering from the sample and standard surfaces.

(d) Errors attributable to diffraction effects in apertures.

(e) Errors attributable to imperfect diffusion of reflected light from the sphere walls (non-Lambertian characteristics).

\section{(f) Baffling.}

To minimize these errors the following procedures and correction methods were applied to the measurements.

\section{Light Losses}

With the aim of reducing light losses, all ports not in use were closed with port plugs.

\section{Unequal Illumination of Sample and Standard} The double beam configuration used in these experiments avoids the substitution error, which is often a feature of single beam measurements (and can be as large as $4 \%-5 \%$ according to the manufacturers ${ }^{6}$ ).

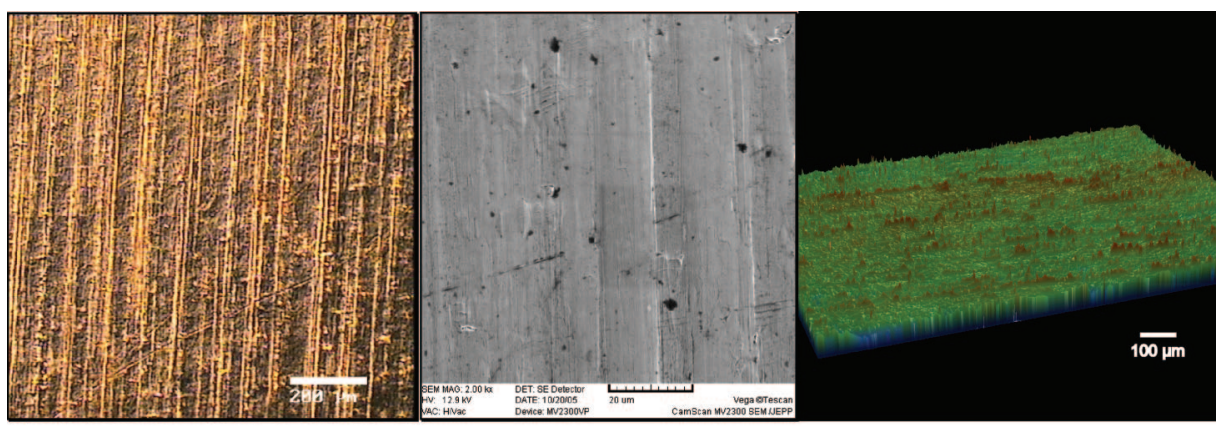

\begin{tabular}{|c|c|c|c|}
\hline \multicolumn{2}{|c|}{$\lambda=1053 \mathrm{~nm}$} & \multicolumn{2}{c|}{$\lambda=532 \mathrm{~nm}$} \\
\hline$A$ & $\sigma$ & $A$ & $\sigma$ \\
\hline $5.6 \%$ & $1.0 \%$ & $57.6 \%$ & $1.3 \%$ \\
\hline
\end{tabular}

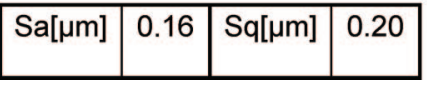

Fig. 7. (Color online) Cu1: commercially pure copper. 
The double beam configuration also has the advantage of reducing the influence of possible laser power fluctuations.

\section{Directional Dependence of Light Scattering}

Light behaves slightly differently inside the sphere when reflected from a rough surface as compared to a relatively flat one. The light incident on a flat surface is subjected to mirrorlike, specular reflection in contrast to rough surfaces where the reflected light is scattered diffusively in many different directions. This produces differences in the number of reflections needed inside the sphere before the light is homoge- neously scattered, which will lead to detector throughput changes. This error can be corrected for by using a combination of diffuse (rough) and specular (flat) reflectance standards.

By knowing the sample's optical diffusivity, $D_{s}$, which is the fraction of reflected light that is scattered diffusively, the reflectance of the sample, $R_{s}$, can be obtained by

$$
R_{s}=S_{s}\left[\left(1-D_{s}\right) \frac{R_{s, r}}{S_{s, r}}+D_{s} \frac{R_{d, r}}{S_{d, r}}\right]
$$

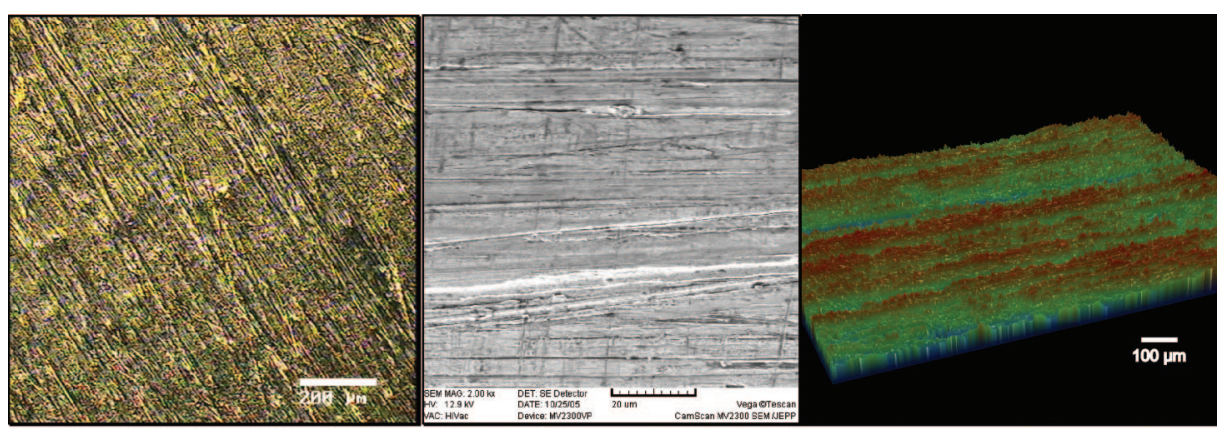

\begin{tabular}{|c|c|c|c|}
\hline \multicolumn{2}{|c|}{$\lambda=1053 \mathrm{~nm}$} & \multicolumn{2}{c|}{$\lambda=532 \mathrm{~nm}$} \\
\hline $\mathrm{A}$ & $\boldsymbol{\sigma}$ & $\mathrm{A}$ & $\sigma$ \\
\hline $10.2 \%$ & $1.0 \%$ & $34.1 \%$ & $2.0 \%$ \\
\hline
\end{tabular}

\begin{tabular}{|l|l|l|l|}
\hline $\mathrm{Sa}[\mu \mathrm{m}]$ & 0.50 & $\mathrm{Sq}[\mu \mathrm{m}]$ & 0.62 \\
\hline
\end{tabular}

(a)

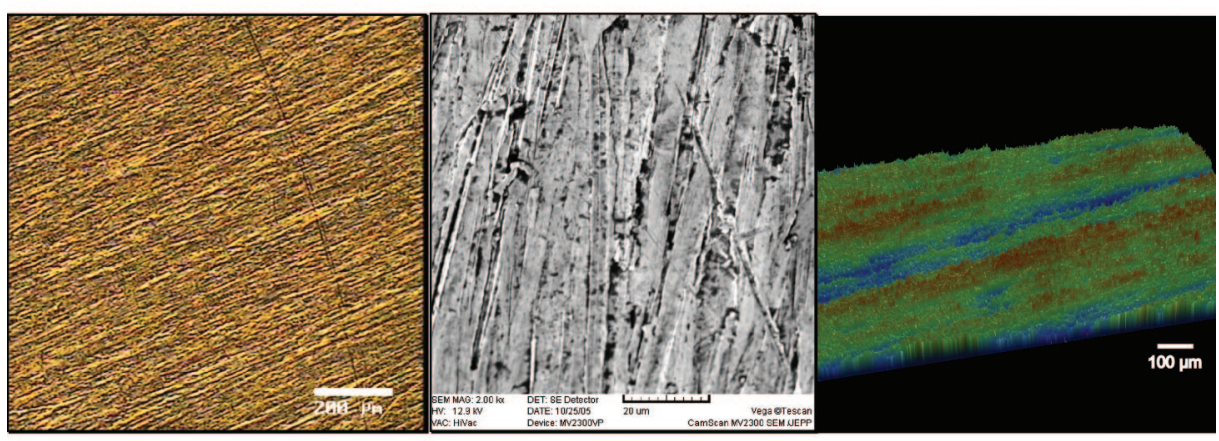

\begin{tabular}{|c|c|c|c|}
\hline \multicolumn{2}{|c|}{$\lambda=1053 \mathrm{~nm}$} & \multicolumn{2}{c|}{$\lambda=532 \mathrm{~nm}$} \\
\hline$A$ & $\sigma$ & $A$ & $\sigma$ \\
\hline $13.3 \%$ & $1.7 \%$ & $37.5 \%$ & $2.1 \%$ \\
\hline
\end{tabular}

\begin{tabular}{|l|l|l|l|}
\hline $\mathrm{Sa}[\mu \mathrm{m}]$ & 0.54 & $\mathrm{Sq}[\mu \mathrm{m}]$ & 0.66 \\
\hline
\end{tabular}

(b)

Fig. 8. (Color online) Brass: (a) Cu2: nonpolished brass, (b) Cu3: polished brass. 


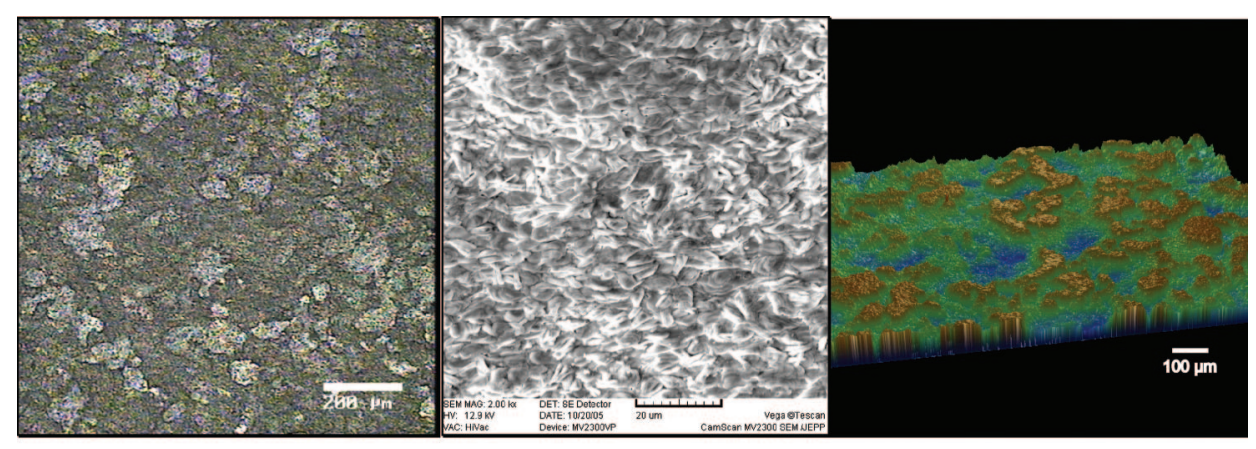

\begin{tabular}{|c|c|c|c|}
\hline \multicolumn{2}{|c|}{$\lambda=1053 \mathrm{~nm}$} & \multicolumn{2}{c|}{$\lambda=532 \mathrm{~nm}$} \\
\hline$A$ & $\sigma$ & $A$ & $\sigma$ \\
\hline $77.6 \%$ & $0.2 \%$ & $60.5 \%$ & $0.3 \%$ \\
\hline
\end{tabular}

\begin{tabular}{|l|l|l|l|}
\hline $\mathrm{Sa}[\mu \mathrm{m}]$ & 2.34 & $\mathrm{Sq}[\mu \mathrm{m}]$ & 2.77 \\
\hline
\end{tabular}

Fig. 9. (Color online) Zn1: Zintec.

where $S_{s}$ is the signal measured with the sample, $R_{s, r}$ is the reflectance of the specular standard (mirror), $S_{s, r}$ is the signal measured with the specular standard, $R_{d, r}$ is the reflectance of the diffuse standard, and $S_{d r}$ is the signal measured with the diffuse standard. ${ }^{7}$

The optical diffusivity can be measured by opening the specular exclusion port (or attaching a light trap) and comparing the signal from the sample to a signal from the diffuse standard (see Fig. 3). The optical diffusivity is then given by

$$
D_{s}=1-\frac{S_{s, \text { spex }} / S_{s}}{S_{d, \text { spex }} / S_{d, r}}
$$

where $S_{s, \text { spex }}$ is the signal measured with the sample and with the specular exclusion port opened, and $S_{d, \text { spex }}$ is the signal measured with the diffuse standard and the specular exclusion port opened. Using this method, a diffusivity of $100 \%$ was assigned to the diffuse standards and $0 \%$ to the specular mirror standard. This error was empirically seen to be almost

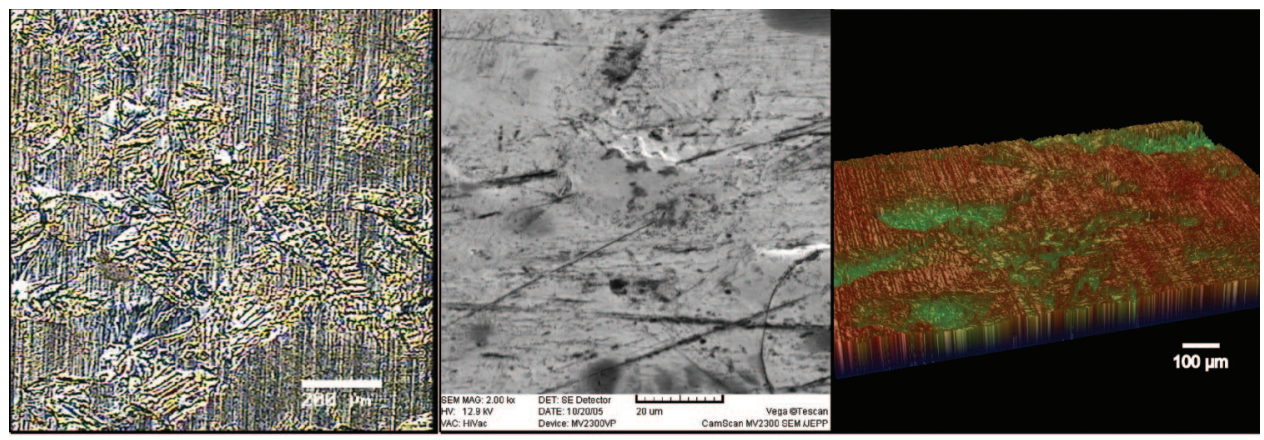

\begin{tabular}{|c|c|c|c|}
\hline \multicolumn{2}{|c|}{$\lambda=1053 \mathrm{~nm}$} & \multicolumn{2}{c|}{$\lambda=532 \mathrm{~nm}$} \\
\hline A & $\sigma$ & $A$ & $\sigma$ \\
\hline $53.8 \%$ & $1.9 \%$ & $33.4 \%$ & $1.4 \%$ \\
\hline
\end{tabular}

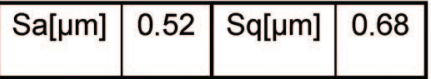

Fig. 10. (Color online) Zn2: Galvatite. 


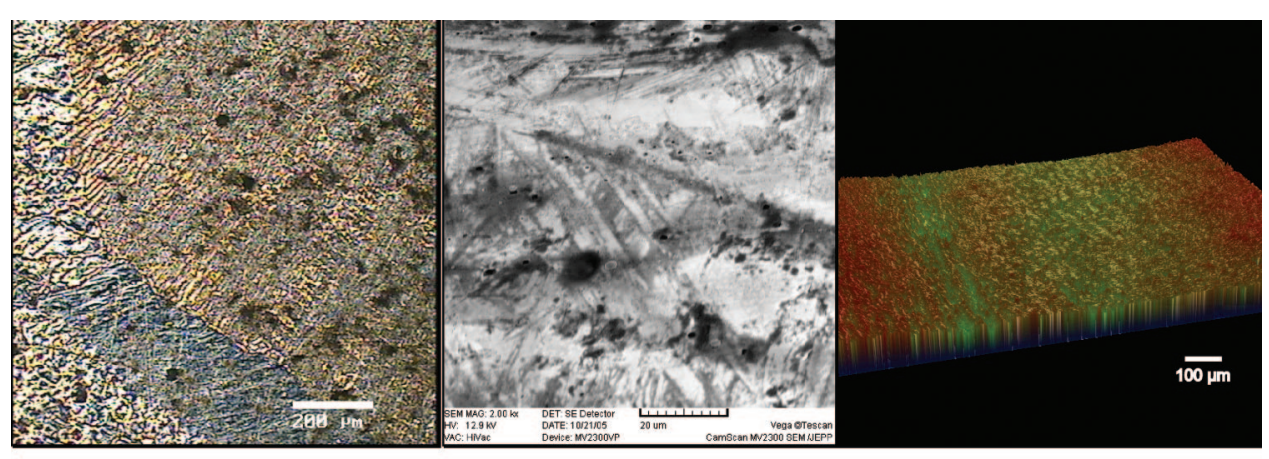

\begin{tabular}{|c|c|c|c|}
\hline \multicolumn{2}{|c|}{$\lambda=1053 \mathrm{~nm}$} & \multicolumn{2}{c|}{$\lambda=532 \mathrm{~nm}$} \\
\hline$A$ & $\sigma$ & $A$ & $\sigma$ \\
\hline $63.1 \%$ & $3.7 \%$ & $48.7 \%$ & $3.9 \%$ \\
\hline
\end{tabular}

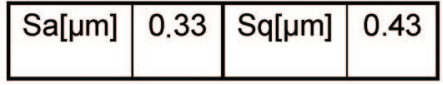

(a)

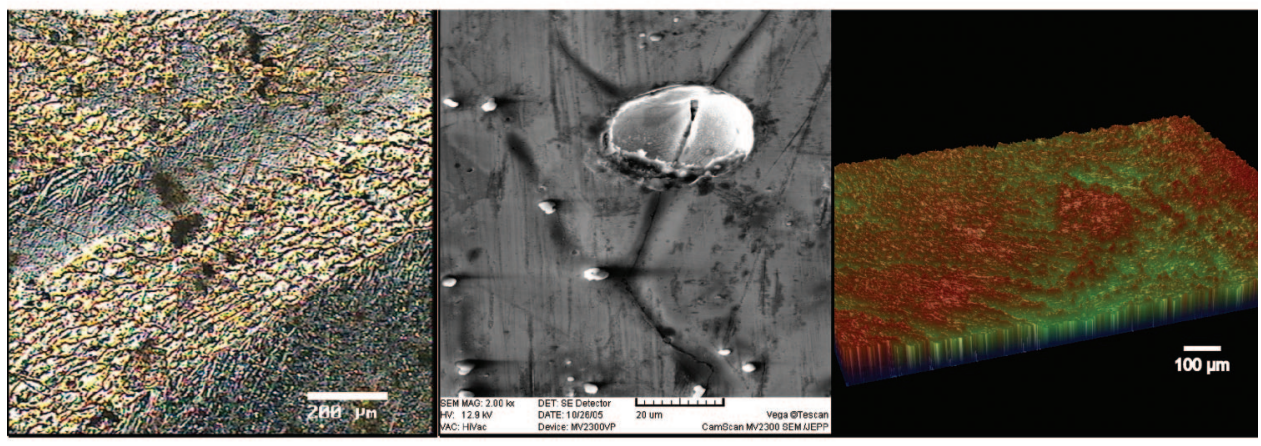

\begin{tabular}{|c|c|c|c|}
\hline \multicolumn{2}{|c|}{$\lambda=1053 \mathrm{~nm}$} & \multicolumn{2}{c|}{$\lambda=532 \mathrm{~nm}$} \\
\hline$A$ & $\sigma$ & $A$ & $\sigma$ \\
\hline $63.0 \%$ & $3.5 \%$ & $45.1 \%$ & $6.6 \%$ \\
\hline
\end{tabular}

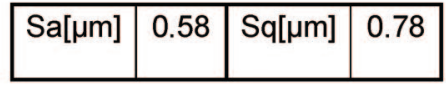

(b)

Fig. 11. (Color online) Hot-dipped galvanized (spangled). (a) Zn3: sample I, (b) Zn4: sample II.

negligible for $\lambda=527 \mathrm{~nm}$, but could amount to more than $1 \%$ in absolute reflectance for $\lambda=1053 \mathrm{~nm}$.

\section{Diffraction Effects in Apertures}

To get a suitable laser spot size on the sample, a lens was put in front of the sample beam entrance port. Owing to diffraction, this produces a characteristic halo around the sample and sample port, which causes a slight error to the measurements. Empirically this was shown to be approximately $0.2 \%$ in absolute reflectance. This error was easily corrected for by measuring the signal with the sample port empty and subtracting this from the signal with the sample in place.

Errors (e) and (f) are due to the specific sphere designs and are not easily corrected for.

Another error was identified in the case of structured samples with contoured surfaces (termed lay in the literature on surface properties). According to Roos $^{8}$ this error can be substantial if care is not taken in positioning the samples correctly in the sample ports. A contoured surface produces a reflected band 
of light (termed specular-diffuse radiation by $\operatorname{Roos}^{8}$ ), which will produce errors if the band crosses the detector (giving too high a reflectance value) or passes through any open beam ports (giving too low a reflectance value). No corrections other than correct positioning was applied in this case.

In experiments such as this it is always important to eliminate the possibility of error as a result of polarization effects. In this work polarization of the laser beam was identified as having a trivial effect upon the results because the angle of incidence of the beam was very close to normal (between $8^{\circ}$ and $9^{\circ}$ ). At these low angles of incidence, polarization effects are minimal.

The measurements were performed in a dark room to minimize the influence of external light sources, such as lamps. Corrections were also made to the current flowing through the photodiode in the absence of light. These dark current measurements were performed before each measurement, which were then subtracted from the measured signals.

Using the correction methods outlined above, the reflectance values of all the diffuse and specular standards were seen to be reproducible to at least within $0.3 \%$ in absolute reflectance. The same reliability can be attributed to the following results for the samples investigated.

\section{Samples and Measurements}

Table 2 lists the different nonferrous samples examined in the survey in terms of their standard identification numbers and their chemical composition. Three types of material groups were studied: $\mathrm{Al}$ alloys, $\mathrm{Cu}$ alloys, and $\mathrm{Zn}$ coatings on mild steel (the substrate having no importance because the light interacts only with the zinc surface). Note that a similar study on mild and stainless steel was also performed and is under preparation as a separate paper.

The corresponding technical surfaces for the 11 samples studied are described in Table 3. The roughness values given in this table are supported by scanning electron microscopy (SEM) and optical microscopy together with profilometry imaging in Section 3 of this paper. In the case of the $\mathrm{Cu}$ and the $\mathrm{Al}$ alloys investigated here, the final cold rolling process gives a directional grain to the surface roughness of these materials. The two electroplated $\mathrm{Zn}$ coatings have a fine isotropic grain structure, and the hot-dipped $\mathrm{Zn}$ coating has a distinctive spangled appearance. All the metal surfaces were measured in the as-received condition.

The samples were laser or mechanically cut from sheets into $30 \mathrm{~mm}$ squares with thicknesses varying between 2 and $6 \mathrm{~mm}$. For each sample, the absorptance measurements were taken at five separate locations; they were then averaged, and a standard deviation was calculated. Each measurement for every location is in turn an average of over 300 data points.

All integrating sphere measurements were carried out relative to a standard of known reflectance. In these experiments a combination of diffuse and specular reflectance standards was utilized. The diffuse

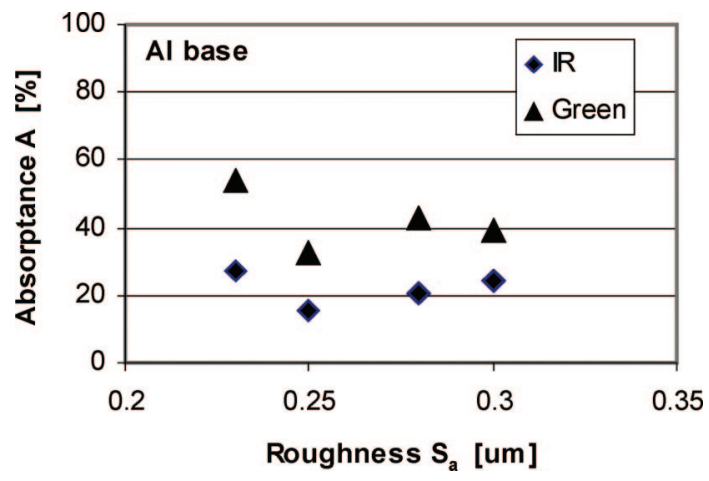

Fig. 12. Absorptance as a function of the surface roughness for the four aluminium alloy samples studied (reference values in Figs. 4-6).

standards had reflectances between $2 \%$ and $99 \%$. The specular standard consisted of an Al-coated mirror, which was calibrated at the Angström Laboratory in Uppsala, Sweden. It had a reflectance of $97.7 \%$ at $1053 \mathrm{~nm}$ and $98.9 \%$ at $527 \mathrm{~nm}$.

The reliability of the measurement method was regarded as satisfactory. The variance $\sigma$ of the measured $A$ values was low. In 15 of 22 cases (11 material samples, 2 wavelengths) the variance of the five measurements taken for each sample was less than $2.0 \%$; only in one case (Zn3, green) was the variance higher than $4 \%$ (namely, 6.6\%).

\section{Results and Discussion}

\section{A. General}

Figures 4-6 for the $\mathrm{Al}$ alloys, Figs. 7 and 8 for the $\mathrm{Cu}$ alloys, and Figs. 9-11 for the Zn coatings present the optical microscopy (OM), SEM, profilometry, and absorptance results obtained in this survey. In each figure the magnification used is 100 times for the OM pictures, 2000 times for the SEM photos, and 5 times for the 3D optical profilometry scans. The surface was measured with a Wykon NT1100 optical profiler, achieving a horizontal resolution of $6.8 \mu \mathrm{m}$ and a vertical resolution in the nanometer range. In the tables below the photos the average absorptance $A$ and standard deviation $\sigma$ are given for both wave-

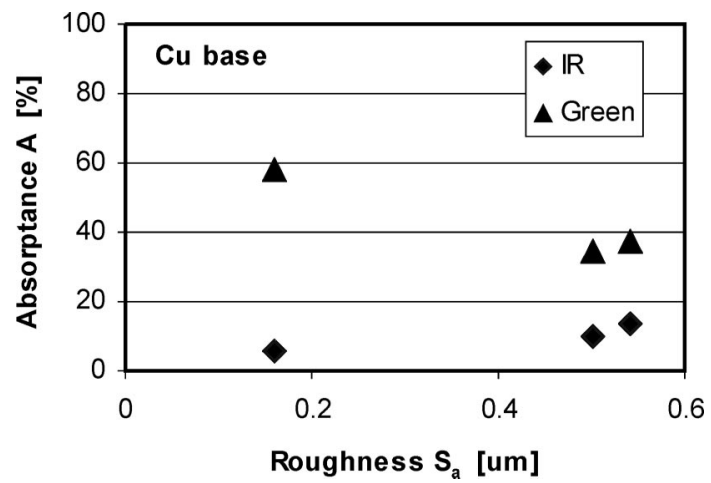

Fig. 13. Absorptance as a function of the surface roughness for the three copper alloy samples studied (reference values in Figs. 7, 8). 


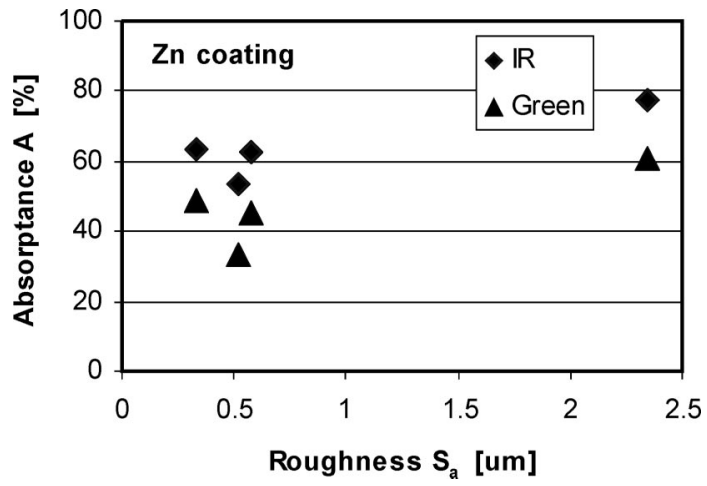

Fig. 14. Absorptance as a function of the surface roughness for the four $\mathrm{Zn}$ coating samples studied (reference values in Figs. 9-11).

lengths as well as the results of the optical profilometry measurements. $S_{a}$ and $S_{q}$ are the average roughness and rms roughness evaluated over the complete 3D surface, respectively. If the surface elevation is given by $Z(x, y), S_{a}$ and $S_{q}$ are evaluated mathematically as follows (with surface area $A$ ):

$$
\begin{aligned}
& S_{a}=\iint_{A}|Z(x, y)| \mathrm{d} x \mathrm{~d} y, \\
& S_{q}=\left(\iint_{A}(Z(x, y))^{2} \mathrm{~d} x \mathrm{~d} y\right)^{1 / 2} .
\end{aligned}
$$

Figures 12, 13, and 14 show the measured absorptance plotted as a function of the surface roughness for $\mathrm{Al}, \mathrm{Cu}$, and $\mathrm{Zn}$ alloys, respectively.

\section{B. Aluminium Alloys}

The measured absorptance as a function of the roughness is plotted in Fig. 12 for the four $\mathrm{Al}$ samples and for the two wavelengths used. It is clear from this figure that there is no clear correlation between surface roughness and absorptance.

Previously published figures put the absorptances of $\mathrm{Al}$ as $4.8 \%$ at $1053 \mathrm{~nm}$ and $7.6 \%$ at $527 \mathrm{~nm} .{ }^{9}$ The figure we measured for our commercially pure $(99 \%$ Al, sample Al1) aluminium sheet for $1053 \mathrm{~nm}$ was $\sim 16 \%$, and this threefold increase is clearly attributable to the oxidized and unpolished nature of our sample. The average figure of $\sim 32 \%$ we obtained for
$527 \mathrm{~nm}$ is surprisingly higher than the previously published value, but the accuracy of this new value is supported by the fact that all the results for $527 \mathrm{~nm}$ were considerably higher than for $1053 \mathrm{~nm}$ over the whole range of $\mathrm{Al}$ samples studied.

The increased absorption for the AA5XXX (samples $\mathrm{Al} 2, \mathrm{Al} 3$ ) and AA6XXX (sample Al4) grades compared with the pure aluminium sample Al1 is probably related to the increase in alloying elements in these grades.

It is interesting to note that there is an absorptance peak for $\mathrm{Al}$ at a wavelength of $800 \mathrm{~nm}$ owing to the atomic band structure of the material. This may, in the future, have positive consequences for $\mathrm{Al}$ processing with high power diode lasers in this wavelength region.

\section{Copper Alloys}

The measured absorptance as a function of the roughness is plotted in Fig. 13 for the three $\mathrm{Cu}$-based samples and for the two wavelengths applied. Once more there is no clear correlation between roughness and absorptance.

Once again the pure $\mathrm{Cu}$ has a higher absorptance $(6 \%$ at $1053 \mathrm{~nm}$ and $58 \%$ at $527 \mathrm{~nm}$ ) than the previously published values [e.g., $2.4 \%$ at $1053 \mathrm{~nm}$ and $38.2 \%$ at $527 \mathrm{~nm}$ (Ref. 9)]. The explanation for the quite large difference in absorptance between the two wavelengths lies in the details of the band structure of $\mathrm{Cu}$, showing a typical interband absorption edge at $\lambda \sim 550 \mathrm{~nm}$. The addition of $37 \%$ of $\mathrm{Zn}$ to the $\mathrm{Cu}$ (to produce brass) increases the absorptance at $1053 \mathrm{~nm}$ but decreases it at $527 \mathrm{~nm}$ for reasons that will be discussed below for the $\mathrm{Zn}$ coatings.

\section{Zinc Coatings}

The measured absorptance as a function of the roughness is plotted in Fig. 14 for the four Zn-coated samples and for the two wavelengths applied. Once again there is no clear correlation between roughness and absorptance at the lower roughness values. There is, however, a noticeable increase in absorptance for the samples with roughness values above $2 \mu \mathrm{m}$.

$\mathrm{Zn}$ coatings come in a wide range of finishes, and three of the most commonly available have been tested here. Of course, we are no longer dealing with a mild steel surface in this case, and the laser is interacting only with the $\mathrm{Zn}$. It can be observed from Fig. 14 that in every case except where $\mathrm{Zn}$ is involved,

\begin{tabular}{|c|c|c|c|c|}
\hline \multirow[b]{2}{*}{ Material } & \multicolumn{2}{|c|}{$\lambda=1053 \mathrm{~nm}$} & \multicolumn{2}{|c|}{$\lambda=527 \mathrm{~nm}$} \\
\hline & Absorptance & Reflectance & Absorptance & Reflectance \\
\hline Al1: Commercially pure $\mathrm{Al}$ & $16 \%$ & $84 \%$ & $32 \%$ & $68 \%$ \\
\hline Al2,3: AA5251, AlMg (average) & $24 \%$ & $76 \%$ & $48 \%$ & $52 \%$ \\
\hline Al4: AA6082, AlMgSi & $24 \%$ & $76 \%$ & $39 \%$ & $61 \%$ \\
\hline $\mathrm{Cu} 1$ : Commercially pure $\mathrm{Cu}$ & $6 \%$ & $94 \%$ & $58 \%$ & $42 \%$ \\
\hline Cu2,3: Brass, CuZn37 (average) & $12 \%$ & $88 \%$ & $38 \%$ & $62 \%$ \\
\hline Zn1-4: Zinc coatings (average) & $64 \%$ & $36 \%$ & $47 \%$ & $53 \%$ \\
\hline
\end{tabular}

Table 4. Summary of the Absorptance and Reflectance Measurements 


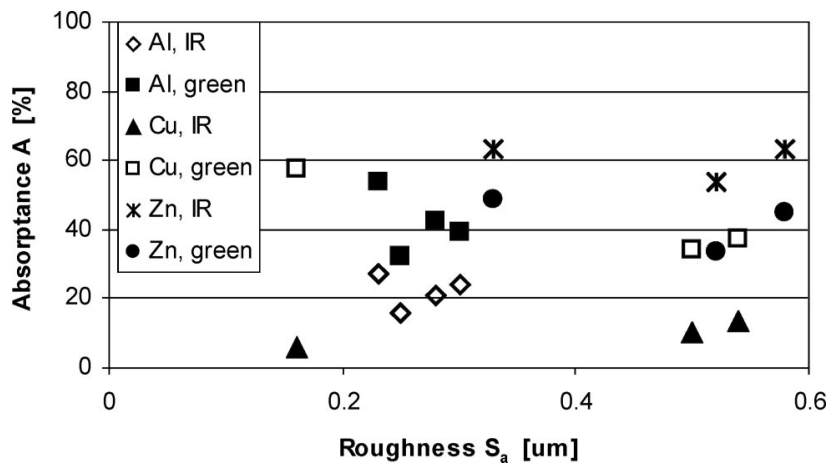

Fig. 15. Absorptance as a function of the surface roughness (below an $S_{a}$ value of $0.6 \mu \mathrm{m}$ ) for all $\mathrm{Al}$ alloys, $\mathrm{Cu}$ alloys, and $\mathrm{Zn}$ coatings studied for both wavelengths.

the absorptance of the metals at $527 \mathrm{~nm}$ is higher than it is at $1053 \mathrm{~nm}$. In the case of brass $(37 \% \mathrm{Zn})$ and the $\mathrm{Zn}$-coated mild steel this trend is reversed. The reason for this lies in the band structure and the absorptance spectra of $\mathrm{Zn}$, the latter of which has a sharp peak at $\lambda \sim 1080 \mathrm{~nm} .^{10}$

The absorptance of the Zintec sample is considerably higher than that of the Galvatite or galvanized (spangled) samples. The SEM photographs and surface roughness measurements indicate that the reason behind this higher absorptance is the considerably rougher surface texture of the Zintec (the Zintec sample gave roughness values that were more than three times greater than any other sample in this whole series of tests).

\section{E. Summary of the Absorptance Measurements}

Table 4 provides a summary of the absorptance and reflectance values obtained for all the various alloys investigated. All these measurements demonstrated that engineering grade metal surfaces have absorptances that are considerably higher than those published for pure, polished surfaces. In the case of $\mathrm{Cu}$ and $\mathrm{Al}$ alloys the absorptance is higher for a wavelength of $527 \mathrm{~nm}$ than for one of $1053 \mathrm{~nm}$. For $\mathrm{Zn}$ this trend was reversed. All the absorptance values are shown in Fig. 15 as a function of the surface roughness with the exception of the Zintec sample.

It is clear from Fig. 15 that, if the surface roughness of the sample is lower than $S_{a}=0.6$, then there is no clear correlation between roughness and absorptance. On the other hand, it appears that absorptance does increase if the surface roughness measurement $S_{a}$ has a value above 2.3 (Zintec; $S_{\alpha}: 2.34 ; A: 77.6$ for $1053 \mathrm{~nm}$, 60.5 for $532 \mathrm{~nm}$ ) this phenomenon is the subject of an ongoing investigation by the present authors.

\section{Conclusions}

Reliable absorptance results have been measured for a range of nonferrous alloys for Nd:YAG and Nd:YLF lasers at their IR and green wavelengths. These results have, as expected, been found to differ substantially from existing published data for pure, polished metals.

The increases in absorptance for engineering grade surfaces can be broadly attributed to surface oxides, roughness, and alloying ingredients, but further study is necessary to isolate the contribution of each factor.

Over the range of surface roughness from approximately $S_{a}=0.15-0.60$ there was no clear correlation between surface roughness and absorptance. However, one much rougher sample $\left(S_{a}=2.34\right)$ indicated that outside this range there could be a roughnessabsorptance correlation.

For the $\mathrm{Al}$ and $\mathrm{Cu}$ alloys studied here the absorptance was higher for the green wavelength than for the IR. This trend was reversed for the $\mathrm{Zn}$ surfaces as a result of the band structure and absorption spectra of Zn.

\section{References}

1. D. Bergström and A. Kaplan, "Mathematical modelling of laser absorption mechanisms in metals: A review," in Proceedings of the 16th Meeting on Mathematical Modelling of Materials Processing with Lasers, D. Schuöcker, A. Kaplan, and A. Kratky, eds. (Igls, Austria, 2003), CD-ROM.

2. K. Blidegn, "The interaction between laser light and metal," Ph.D. dissertation (Technical University of Denmark, 1997).

3. D. J. Price, "The temperature variations of the emissivity of metals in the near infrared," Proc. Phys. Soc. London 47, 131-138 (1947).

4. D. Bergström, D. A. Kaplan, and J. Powell, "Laser absorptance measurements in opaque solids," in Proceedings of the Tenth Nordic Laser Materials Processing Conference, A. Kaplan, ed. (Piteå, Sweden, 2005), pp. 91-115.

5. F. J. J. Clarke and J. A. Compton, "Correction methods for integrating sphere measurements of hemispherical reflectance," Color Res. Appl. 11, 253-262 (1986).

6. Labsphere Application Note 01, "Methods for single beam substitution error for integrating sphere spectroscopy accessories," http://www.labsphere.com.

7. A. Seifter, K. Boboridis, and A. W. Obst, "Emissivity measurements on metallic surfaces with various degrees of roughness: a comparison of laser polarimetry and integrating sphere reflectometry," in Proceedings of the 15th Symposium on Thermophysical Properties (Boulder, Colorado, 2003), pp. 547-560.

8. A. Roos, C. G. Ribbing, and M. Bergkvist, "Anomalies in integrating sphere measurements on structured samples," Appl Opt. 27, 3828-3832 (1988).

9. CRC Handbook of Chemistry and Physics, 73rd ed. (CRC Press, 1989).

10. J. H. Weaver, D. W. Lynch, and R. Rosei, "Optical properties of single-crystal Zinc," Phys. Rev. B 8, 2829-2835 (1972). 